\title{
Multidisciplinary approach to converting power chair into motorized prone cart
}

\author{
Steven W. Brose, DO; ${ }^{1-2 *}$ Eisha Wali, BS ${ }^{2}$ \\ ${ }^{1}$ Spinal Cord Injury Service, Louis Stokes Cleveland Department of Veterans Affairs Medical Center, Cleveland, $\mathrm{OH}$; \\ Department of Specialty Medicine, Ohio University Heritage College of Osteopathic Medicine, Athens, OH; Cleveland \\ FES Center, Cleveland, $\mathrm{OH} ;{ }^{2}$ Department of Physical Medicine and Rehabilitation, Case Western Reserve University \\ School of Medicine, Cleveland, Ohio
}

\begin{abstract}
Pressure ulcers remain a major source of morbidity and mortality in veterans with neurologic impairment. Management of pressure ulcers typically involves pressure relief over skin regions containing wounds, but this can lead to loss of mobility and independence when the wounds are located in regions that receive pressure from sitting. An innovative, lowcost, multidisciplinary effort was undertaken to maximize quality of life in a veteran with a thoracic-4 level complete spinal cord injury and a stage 4 ischial wound. The person's power wheelchair was converted into a motorized prone cart, allowing navigation of the Department of Veterans Affairs spinal cord injury hospital ward and improving socialization while relieving pressure on the wound. Physical and occupational therapy assisted with the reconfiguration of the power chair and verified safe transfers into the chair and driving of the device. Psychology verified positive psychosocial benefit, while nursing and physician services verified an absence of unwanted pain or skin injury resulting from use of the device. Further investigation of ways to apply this technique is warranted to improve the quality of life of persons with pressure ulcers.
\end{abstract}

Key words: decubitus, ischial, motorized, power, pressure, prone cart, rehabilitation, spinal cord injury, wheelchair, wound.

\section{INTRODUCTION}

Pressure ulceration is a common and significant medical complication that occurs following neurologic injuries such as spinal cord injury (SCI) [1-3]. Pressure ulceration can decrease quality of life, increase care requirements, and lead to further medical complications such as osteomyelitis, bacteremia, and sepsis [4-6]. Pressure ulceration in persons with SCI increases cost of medical care and is a common cause of hospitalization in this population [7]. A key component of managing pressure ulceration is minimizing pressure in the region of ulceration [8], which in ischial ulcers can include significant limitations placed on time allowed for sitting. Increased sitting time has been implicated in pressure ulcer recurrence [9-10]. Although decreased sitting times can be beneficial for ischial wound healing, there are several negative consequences of prescribing prolonged bed rest, including deconditioning, respiratory compromise, and psychosocial effects associated with limited mobility [5]. Use of prone carts can alleviate some of these concerns, but not all persons with neurologic impairment are able to use traditional manual prone carts and specialized motorized prone carts are not always available. In certain cases, it may be possible to convert an individual's existing wheelchair into a motorized prone cart for the duration

\footnotetext{
Abbreviation: $\mathrm{SCI}=$ spinal cord injury.

*Address all correspondence to Steven W. Brose, DO; Louis Stokes VA Hospital-Spinal Cord Injury, 10701 East Blvd, Cleveland, $\mathrm{OH}$ 44106; 216-791-3800, ext 3658; fax: 216707-5936. Email: steven.brose@va.gov http://dx.doi.org/10.1682/JRRD.2014.01.0027
} 
that it is needed. A detailed description of this innovative intervention has not yet been described in the literature. This report describes a multidisciplinary effort to improve mobility and quality of life in a veteran with SCI and ischial pressure ulceration, while complying with sitting time limitations, by converting a power wheelchair into a motorized prone cart.

\section{METHODS}

\section{Case Description}

A 67 yr-old male veteran with a thoracic-4 level complete SCI was admitted to the Department of Veterans Affairs SCI service for management of a right ischial ulcer with osteomyelitis measuring $2.5 \mathrm{~cm}$ length by $2 \mathrm{~cm}$ width and initially unstageable depth due to eschar. The wound was found to extend to the depth of the ischium after eschar débridement. The veteran was 67 in. (170.2 cm) in height and $198.7 \mathrm{lb}(90.1 \mathrm{~kg})$ in weight and had a body mass index of 31.19, which is classified as obese.

The treatment plan included avoidance of sitting to decrease pressure on the wound, nutritional support, education on proper turning, and wound ultrasound and electrical stimulation intended to stimulate healing. The wound progressively improved throughout the hospitalization, but the person with SCI and ischial wound noted that his quality of life suffered greatly. He considered leaving the hospital against medical advice because of the lack of socialization and decreased mobility. There was limited access to a motorized prone cart at the time because of a large population of persons with wounds admitted to the SCI unit. This prompted the person with SCI and ischial ulceration, who was an engineer by profession, to inquire whether it was possible to convert his Permobil C500 ${ }^{\complement}$ wheelchair (Permobil Inc; Lebanon, Tennessee) into a motorized prone cart. The multidisciplinary team was intrigued at this request and found no prior literature definitively describing the process to accomplish such an effort. Within 2 wk of his request, a multidisciplinary team of SCI medical professionals successfully accomplished this conversion.

\section{Reconfiguration Method}

Figure 1 shows a C500 chair before reconfiguration, facing the same direction as the converted chair.

The linkage to the power recline mechanism was reconfigured to attain $175^{\circ}$ of recline, which was $20^{\circ}$

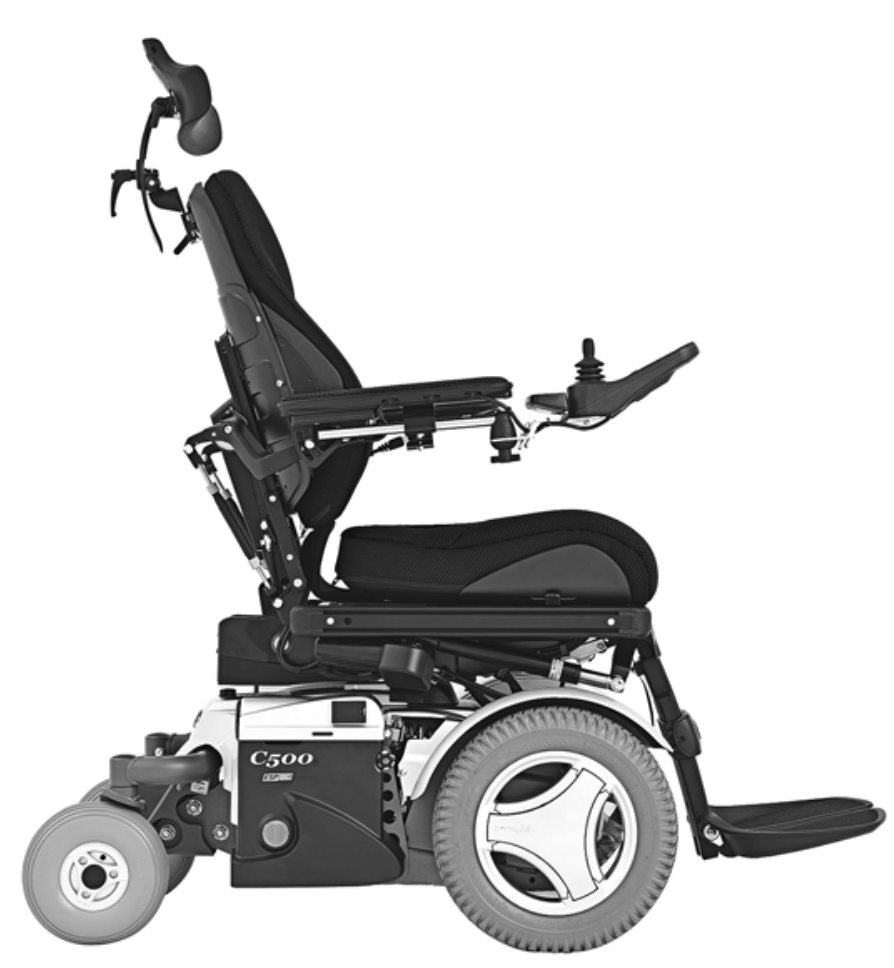

Figure 1.

Lateral view of Permobil C500 chair. Photo used by permission from Permobil Inc (Lebanon, Tennessee).

more than had originally been available. The linkage to the power elevating center mount leg rest was reconfigured so that the center mount stalk was roughly parallel with the seat pan when the leg rests were fully elevated. A modified cushion was used to adjust for the $3 \mathrm{in}$. discrepancy between the back pan and the seat pan in the fully reclined position. To support the lower limbs, a spare padded $16 \mathrm{in}$. width by 15 in. height $\mathrm{AES}^{\circledR}$ back pan (Sunrise Medical; Fresno, California) was mounted to the wheelchair by removing the calf pads and bolting the back pan to the calf pad mounting brackets. This adjustment helped reduce pressure under the knees. The footplates were remounted in the center mount stalk to remove them as a source of interference. The lateral thigh supports were reconfigured to bridge the gap between the cushions supporting the trunk and the lower limbs.

The armrests and joystick were reverse-mounted and both axes were electronically inverted through a programming adjustment, to maintain normal directions for steering (Figures 2-4). Figure 2 displays a midway point of the conversion from the power chair into a motorized prone cart and shows that the chair had to be driven in 


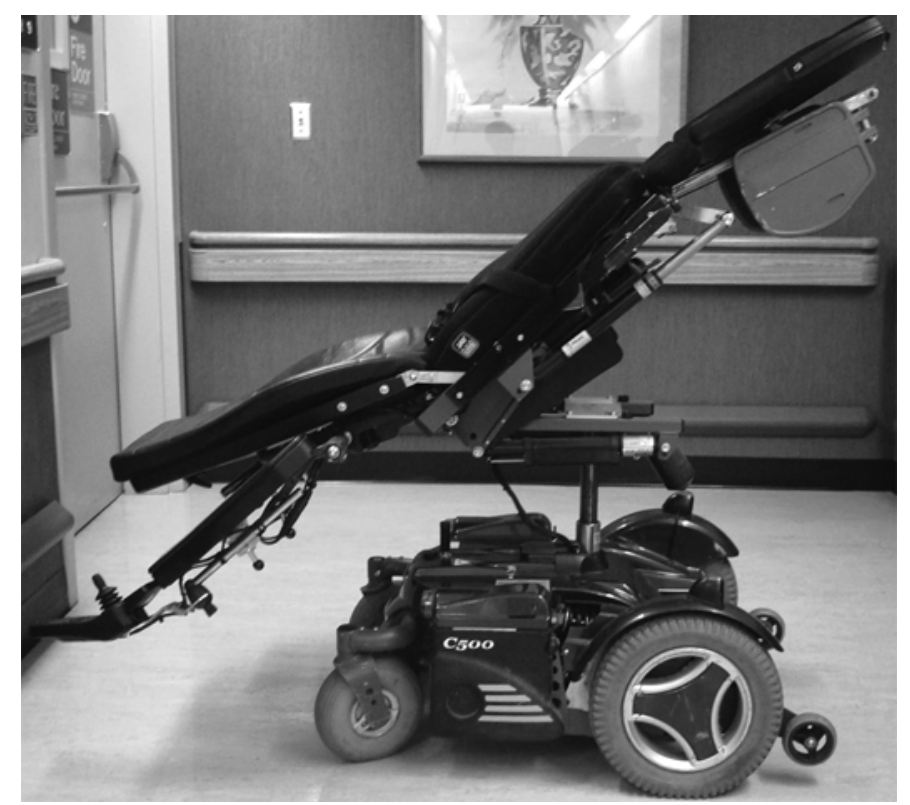

Figure 2.

Chair in conversion to motorized prone cart.

reverse to allow the person with SCI to face forward while driving. Note that the device was not used in this degree of tilt, but is rather shown at this angle to provide a view of the wheelchair components.

\section{RESULTS AND DISCUSSION}

\section{Multidisciplinary Team Assessment}

\section{Nursing}

There were no reported issues with skin management, autonomic dysreflexia, urinary catheter, or bowel management resulting from prone positioning on the cart. The motorized cart was more comfortable and easier to use for the patient than the manual carts he used previously.

\section{Physician}

While utilizing the cart, the patient reported no shoulder pain. There was no reflex bowel or bladder activation and no observed negative effects on respiration.

\section{Physical and Occupational Therapy}

The person with SCI and ischial ulceration was able to transfer from supine on bed to prone on the modified prone cart with minimal assistance, as assessed by the Functional Independence Measure scale [11], needing

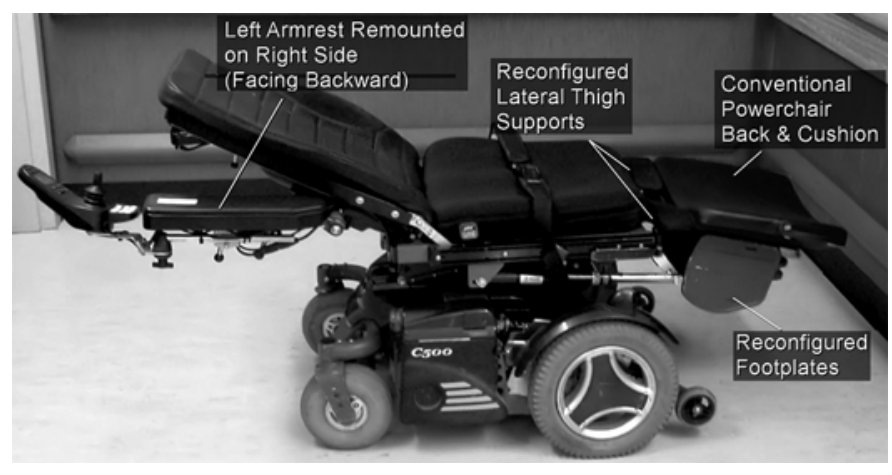

Figure 3.

Chair converted to motorized prone cart, with components labeled.

help to manage his lower limbs and pelvis. Pillows and a two-person assist were required to bridge the gap between the prone cart and the bed. He was able to negotiate the SCI ward at a modified independent level. The person with SCI and ischial ulceration had no complaints regarding the comfort level of the modified prone cart. Pressure mapping showed safe pressure distribution overall with some elevated pressure at the right knee, which was alleviated by using added cushioning.

The reconfiguration of the Permobil C500 wheelchair took approximately $1 \mathrm{~h}$ once the planned changes were decided upon. Usability and safety testing were completed, and it was determined that the converted chair should pose no greater safety risks than a standard powered prone cart, provided the patient did not tilt the chair beyond $30^{\circ}$.

There was concern that driving the chair in reverse for extended periods had potential to place increased strain upon the motor. Support from the manufacturers confirmed concerns that permanent use of the chair in this reconfiguration could face challenges due to increased motor strain. Additionally, because the chair was driving in reverse and there was some uncertainty regarding stability of the modified chair on inclines, the chair was applied only for indoor level surface use. Additional testing would be needed to verify the effect of extended driving in reverse.

Potential longer term modifications that were considered included reversing direction of the chair on the base, which could potentially reduce strain on the motor by allowing the chair to run in the forward direction. This reversal was not conducted because of the relatively shorter term goals of the patient and the more extensive 


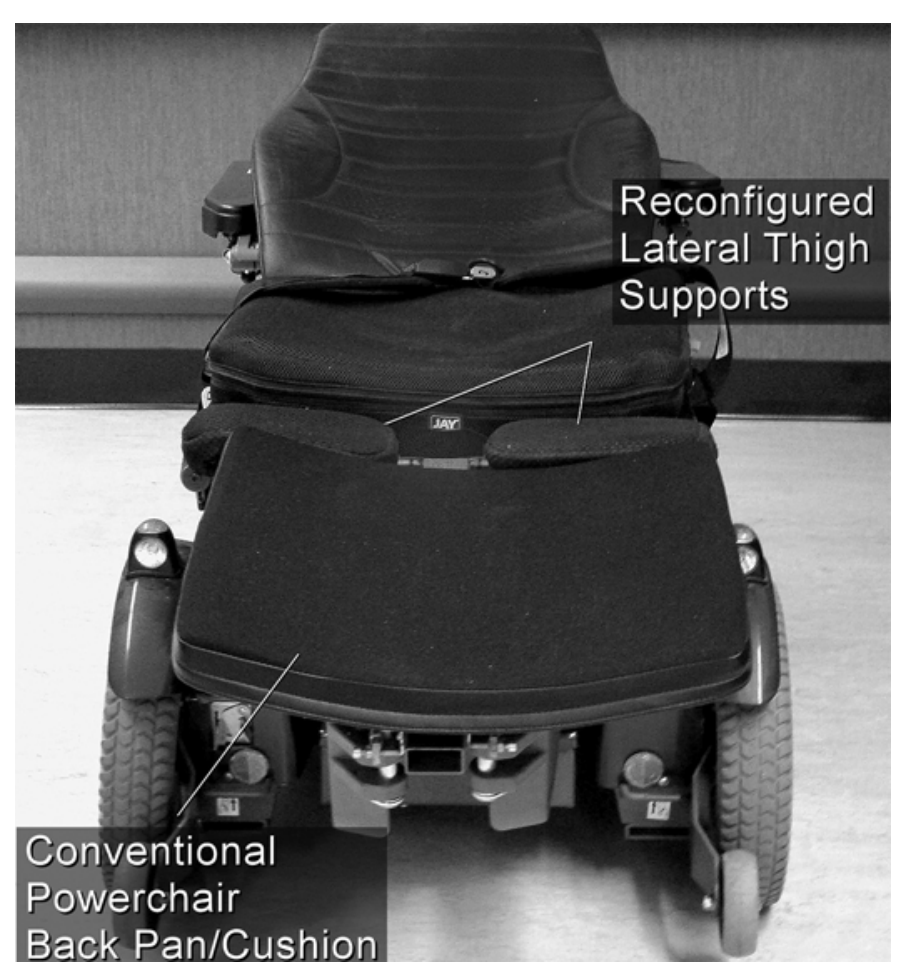

Figure 4.

Chair converted to motorized prone cart, with components labeled.

technical requirements of conducting such a conversion, but in select longer term use situations this could potentially be an option for consideration to reduce motor strain. Adjusting the position of the footrest to provide additional protection for the feet during turns is also an option; an extension bar could be connected around the feet to protect the feet and ankles.

\section{Psychology and Social Work}

The person with SCI and ischial ulceration was well adjusted to his chronic SCI and was employed, enjoyed sports, and had good family support. It was important for him to get out of bed so he could maintain his independence and social interaction. He had good insight, no prior mental health concerns, and was deemed likely to adhere to treatment recommendations protocols when utilizing the modified cart.

\section{User Perspective}

The person with SCI and ischial ulceration was pleased with the prone cart and expressed a desire to recommend it to other patients facing similar medical concerns (Figures 5-6). The adapted prone cart provided him with a mode of transportation available at any time that he could use despite his sitting time limitations. One major benefit he cited was the ability to go to the hospital canteen whenever he pleased, since previously he was only able to purchase items when he had visiting family members who could do so for him. In describing the emotional and psychological effects of the prone cart, the user stated, "A merry heart does good like a medicine; being in the prone cart made me merry."

\section{CONCLUSIONS}

The prone configuration allowed a person with SCI and ischial ulceration to leave his room and navigate the hospital ward, improving satisfaction while avoiding pressure on his wound. Specialized modifications of power chairs are frequently conducted in rehabilitation institutions, and this unique modification has the potential to be used in cases such as the one described here when purpose-built motorized prone carts are not available. Investigating ways to decrease mechanical chair strain and wider use of this modification for longer term use, ideally with further assistance of wheelchair manufacturers to optimize specific modifications, has the potential to improve quality of life and patient compliance in cases of

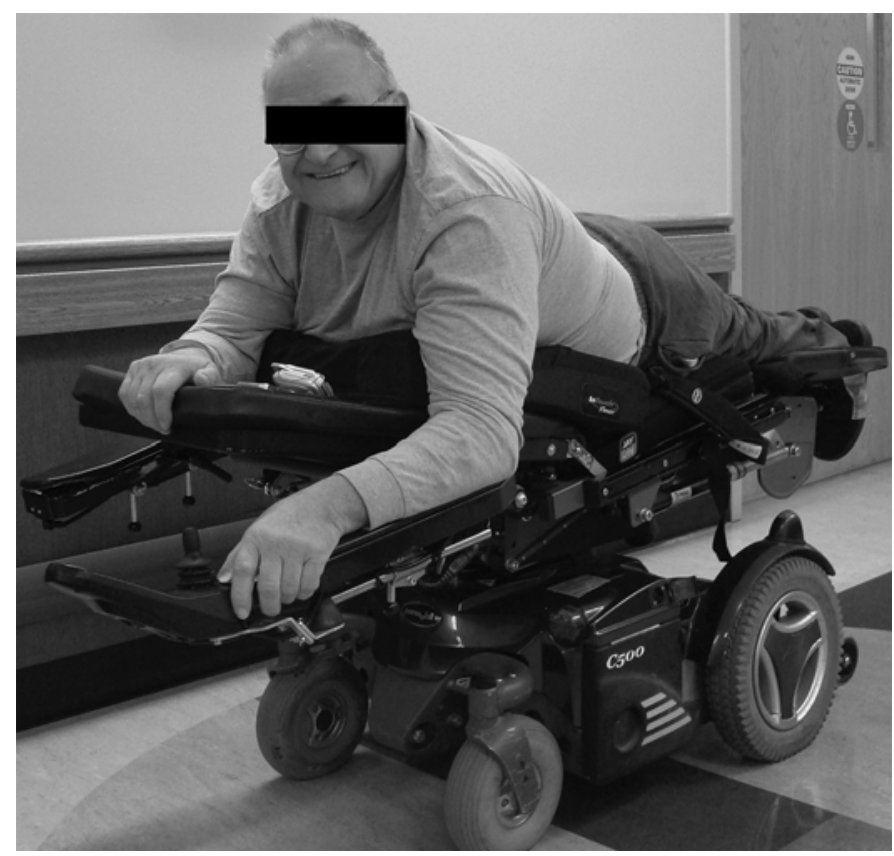

Figure 5.

User on his converted chair. 


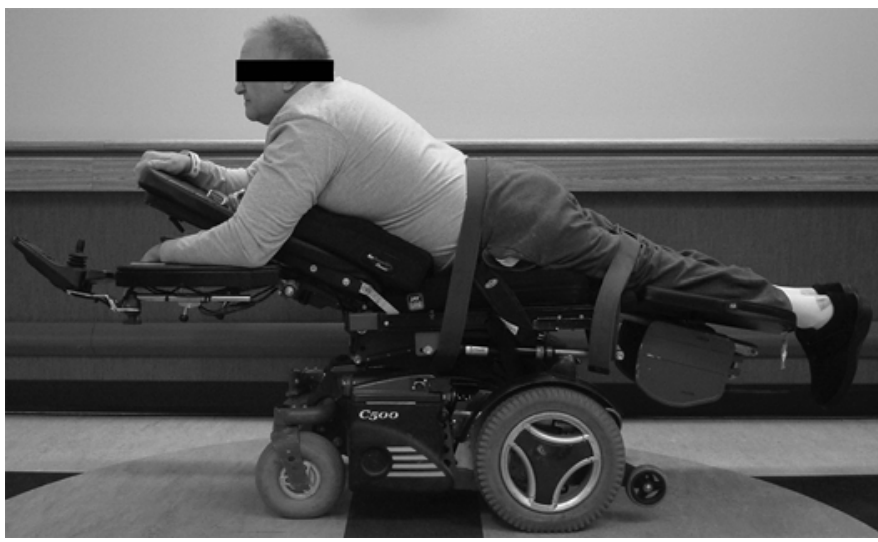

Figure 6.

User on his converted chair.

difficult wound management. The benefits experienced with this reconfiguration indicate that increased use of purpose-built motorized prone cards may be beneficial on hospital wards with high frequency of treating persons with ischial wounds.

\section{ACKNOWLEDGMENTS}

\section{Author Contributions:}

Concept, design, manuscript preparation, subject contact: S. W. Brose, E. Wali.

Financial Disclosures: No commercial party having a direct financial interest in the results of the research supporting this article has or will confer a benefit upon the author(s) or upon any organization with which the author(s) is/are associated. The device to which investigational modifications were made was a standard Permobil C500 power wheelchair.

Funding/Support: This material was based on work supported by Department of Veterans Affairs Rehabilitation Research and Development 822.

Institutional Review: Subject provided consent for publication of this report and signed a media release form providing legal ownership of images.

\section{REFERENCES}

1. Bates-Jensen BM, Guihan M, Garber SL, Chin AS, Burns SP. Characteristics of recurrent pressure ulcers in veterans with spinal cord injury. J Spinal Cord Med. 2009;32(1):34-42. [PMID:19264047]

2. Garber SL, Rintala DH. Pressure ulcers in veterans with spinal cord injury: A retrospective study. J Rehabil Res
Dev. 2003;40(5):433-41. [PMID:15080228]

http://dx.doi.org/10.1682/JRRD.2003.09.0433

3. McKinley WO, Jackson AB, Cardenas DD, DeVivo MJ. Long-term medical complications after traumatic spinal cord injury: A regional model systems analysis. Arch Phys Med Rehabil. 1999;80(11):1402-10. [PMID:10569434] http://dx.doi.org/10.1016/S0003-9993(99)90251-4

4. Backhaus M, Citak M, Tilkorn DJ, Meindl R, Schildhauer TA, Fehmer T. Pressure sores significantly increase the risk of developing a Fournier's gangrene in patients with spinal cord injury. Spinal Cord. 2011;49(11):1143-46.

[PMID:21788955] http://dx.doi.org/10.1038/sc.2011.75

5. Henzel MK, Bogie KM, Guihan M, Ho CH. Pressure ulcer management and research priorities for patients with spinal cord injury: Consensus opinion from SCI QUERI Expert Panel on Pressure Ulcer Research Implementation. J Rehabil Res Dev. 2011;48(3):xi-xxxii. [PMID:21480093] http://dx.doi.org/10.1682/JRRD.2011.01.0011

6. Citak M, Backhaus M, Tilkorn DJ, O’loughlin PF, Meindl R, Muhr G, Fehmer T. Necrotizing fasciitis in patients with spinal cord injury: An analysis of 25 patients. Spine. 2011; 36(18):E1225-29. [PMID:21325991] http://dx.doi.org/10.1097/BRS.0b013e3182059950

7. Chan BC, Nanwa N, Mittmann N, Bryant D, Coyte PC, Houghton PE. The average cost of pressure ulcer management in a community dwelling spinal cord injury population. Int Wound J. 2013;10(4):431-40. [PMID:22715990]

8. Ho CH, Bogie K. The prevention and treatment of pressure ulcers. Phys Med Rehabil Clin N Am. 2007;18(2):235-53. [PMID:17543771] http://dx.doi.org/10.1016/j.pmr.2007.02.004

9. Whitney J, Phillips L, Aslam R, Barbul A, Gottrup F, Gould L, Robson MC, Rodeheaver G, Thomas D, Stotts N. Guidelines for the treatment of pressure ulcers. Wound Repair Regen. 2006;14(6):663-79. [PMID:17199832] http://dx.doi.org/10.1111/j.1524-475X.2006.00175.x

10. Guihan M, Garber SL, Bombardier CH, Durazo-Arizu R, Goldstein B, Holmes SA. Lessons learned while conducting research on prevention of pressure ulcers in veterans with spinal cord injury. Arch Phys Med Rehabil. 2007; 88(7):858-61. [PMID:17601465] http://dx.doi.org/10.1016/j.apmr.2007.03.014

11. Hamilton BB, Granger CV, Sherwin FS, Zielezny M, Tashman JS. A uniform national data system for medical rehabilitation. In: Fuhrer JM, editor. Rehabilitation outcomes: Analysis and measurement. Baltimore (MD): Paul $\mathrm{H}$. Brookes Publishing Co; 1987. p. 137-47.

Submitted for publication January 29, 2014. Accepted in revised form July 22, 2014. 
JRRD, Volume 51, Number 9, 2014

This article and any supplementary material should be cited as follows:

Brose SW, Wali E. Multidisciplinary approach to converting power chair into motorized prone cart. J Rehabil
Res Dev. 2014;51(9):1377-82.

http://dx.doi.org/10.1682/JRRD.2014.01.0027

\begin{tabular}{|c|c|}
\hline $\begin{array}{l}\text { Mu suverssons scaresseor } \\
\sqrt{ } \text { iThenticate }\end{array}$ & Crossref hEnвE \\
\hline 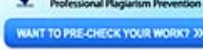 & $\begin{array}{l}\text { CROSSREF. ORG } \\
\text { THE CIIATION LINKL }\end{array}$ \\
\hline
\end{tabular}

